\title{
Microstructure Model for Predicting the Sorptivity of Concrete Mixtures
}

\author{
Fayez Moutassem \\ Department of Civil and Infrastructure Engineering, American University of Ras Al Khaimah, United Arab Emirates
}

Received January 14, 2020; Revised March 12, 2020; Accepted March 19, 2020

Copyright@2020 by authors, all rights reserved. Authors agree that this article remains permanently open access under the terms of the Creative Commons Attribution License 4.0 International License

\begin{abstract}
Durability of concrete structures is determined by the mass transport properties of concrete. The performance of concrete exposed to aggressive environments is a function mainly of the penetrability of the pore structure i.e. the rate of absorption (sorptivity) due to capillary rise. This study involves the development of a predictive sorptivity microstructure model accounting for the type of cement, cement degree of hydration, mixtures proportion, aggregates gradation and packing density, and air content. This paper presents the formulation and validation of a sorptivity model. An experimental program is designed to evaluate the proposed model. Evaluation of the proposed model revealed that the model is a good fit to the experimental data and does not contain outliers or discerning pattern. The corresponding standard error and correlation coefficient are $0.00039 \mathrm{~mm} / \mathrm{s}^{1 / 2}$ and 0.89 , respectively. Results of statistical evaluation revealed that the proposed model is significant in its prediction of the outcome, where the p-value was found to be less than 0.001 . The proposed predictive sorptivity model can be employed in the design of concrete mixtures to meet specific durability requirements as a priority and ensure quality control. Furthermore, the proposed model can be utilized to improve the durability prediction of concrete mixtures.
\end{abstract}

Keywords Concrete, Sorptivity, Absorption, Water Penetration, Durability, Packing Density, Porosity, Transport Properties

\section{Introduction}

Durability of concrete structures is determined by the mass transport properties of concrete. Numerous research studies have shown that mass transport properties of concrete, namely permeability and sorptivity are directly related to the durability of concrete structures, in which higher sorptivity or permeability leads to less durable concretes [1]. The most important parameter leading to premature deterioration of concrete structures is the access of moisture into the concrete. The transport of liquid through concrete is usually described by absorption and permeability. Absorption is a material property, which reflects the ability of the concrete to transmit liquids by capillary suction to fill the pore spaces available within the concrete microstructure. The rate of absorbed volume of liquids per unit area gives an indication of the pore structure of concrete. The sorptivity test measures the capillary suction of concrete while in contact with water. The increase in the mass of a specimen due to the absorption of water by capillary suction is measured for certain time intervals when the surface of the unsaturated concrete specimen is exposed to water ingress. Therefore, sorptivity is a property related to capillary effects and is defined as the gradient of volume of water absorbed per unit area of section surface and the square root of the absorption time [2]. Sorptivity can be evaluated using Equation 1:

$$
\mathrm{M}(\mathrm{t})=\rho \mathrm{A}_{\mathrm{f}} \mathrm{St}^{1 / 2}
$$

Where: $M(t)$ is the mass of fluid uptake; $t$ is time; $\rho$ is the density of fluid; $A$ is the cross sectional area in contact with fluid; and $S$ is the sorptivity. According to ASTM C1585 [3], sorptivity is determined for each mix using linear regressive analysis, in which the absorption, $M(t) / \rho A$, at certain time intervals is plotted against the square root of time and then the slope of the best fit line is determined.

The rate of liquid penetration into the concrete depends on its pore structure, which depends on the materials and mixture proportions. Therefore, the main influential variables include the water-to-cement ratio of the concrete, the degree of cement hydration, the amount of air, and the use of supplementary cementing materials [4]. Numerous researches have revealed that an increase in the water to cement ratio results in an increase in the void content and consequently a reduction in both the strength and durability of hardened concrete [2,5]. The degree of cement hydration 
depends mainly on the type and amount of cement paste, age of concrete, and curing conditions. The older the concrete the greater the amount of hydration, which leads to a more highly developed pore structure. Proper curing of concrete is necessary to ensure the existent of a sufficient amount of water for cement hydration to occur over time. Research has also shown that the packing density of the aggregates used in concrete impacts the hardened properties of concrete [5,6]. Dense packing of the aggregates through improved proportions and gradations would lead to an increase in strength and reduction in the porosity of hardened concrete due to the reduction in the amount and size of voids in concrete [5].

Therefore, in order to design for a more durable and less permeable concrete at the concrete mixture proportioning stage, it is necessary to develop a model which can predict the rate of water absorption into concrete. This paper presents the research findings and is divided into two main parts. The first part provides the mathematical description of the proposed sorptivity model. The second part presents the evaluation and model validation protocol adopted, which includes an experimental program carried out by the author.

\section{Sorptivity Model Development}

\subsection{General Form and Main Variables}

The proposed model for predicting the sorptivity is function of concrete mixture and comprises of: cement hydration model to account for the chemical composition of cement and the degree of cement hydration, and variables accounting for the packing density of aggregates, capillary porosity and air voids. Accordingly, the general form of the sorptivity model is a function of the following main variables (Equation 2):

$$
\mathrm{S}=\mathrm{F}\left(\alpha, \phi_{\mathrm{agg}}, \mathrm{w} / \mathrm{c}, \mathrm{V}_{\mathrm{a}}\right)
$$

Where: $\alpha$ is the degree of hydration of cement; $\phi_{\text {agg }}$ is the packing density of aggregates; $w / c$ is the water to cementing materials ratio; and $V_{a}$ is the volume fraction of air entrapped and/or entrained relative to total volume of the mix.

\subsection{Cement Hydration Model}

Portland cement reacts with water to form two major products, calcium silicate hydrates and calcium hydroxide. Numerous researchers have studied and modeled cement hydration as it provides the critical link for concrete evolution [7]. The degree of cement hydration is defined as the ratio between the quantity of hydrated cement to the original quantity. It is influenced by the cement composition and fineness, the water-to-cement ratio, mineral admixtures, concrete age, temperature, and moisture content [8].
Research has revealed the existence of a linear relationship between the compressive strength of concrete and the degree of cement hydration that depends on the water to cement ratio [9]. With other variables constant, an increase in the degree of cement hydration leads to an increase in strength and durability of hardened concrete. Research has also shown that cement starts hydrating and gaining strength when the degree of cement hydration $(\alpha)$ reaches a threshold value called the critical degree of hydration $\left(\alpha_{c r}\right)$. For Portland cement, $\alpha_{c r}$ can be estimated by multiplying $w / c$ with a constant, $k$, of 0.43 [10]. Limited number of researchers have developed strength prediction models that relate the compressive strength of concrete to the degree of cement hydration $[6,8,11]$. Since an increase in $\alpha$ beyond $\alpha_{c r}$ results in a linear increase in strength and a reduction in concrete permeability, in this study $\alpha$ is related to Sorptivity (S) using the following relationship (Equation $3)$ :

$$
\mathrm{S} \propto 1 /\left(\alpha-\alpha_{\mathrm{cr}}\right), \alpha>\alpha_{\mathrm{cr}}
$$

For prediction of $\alpha$, the Schindler and Folliard [8] cement hydration model was adopted in this study because of its general form, completeness, and good predictions.

\subsection{Capillary Pores and Air Pores}

Concrete $w / c$ influences the amount of capillary pores, in which an increase in $w / c$ results in an increase in capillary pores leading to a reduction in strength and an increase in permeability [7]. In addition, the amount of air pores, either entrapped or entrained, reduces strength and increases permeability. Popovics' relationship between strength and amount of pores, a modification of Abram's model [12], has shown a high degree of predictability $[6,13]$ and was therefore, adopted in this study (Equation 4):

$$
\mathrm{S} \propto \mathrm{B}^{(\mathrm{w}+\mathrm{V}) / \mathrm{c}}
$$

Where: $\left(w+V_{a}\right) / c$ is the weight fraction of water and air relative to cementing materials in the concrete mix; and $B$ is a calibration constant accounting for the shape of the tested specimen and the test conditions.

\subsection{Packing Density}

The packing density property gives an indirect measurement of concrete porosity and accounts for both the gradation and proportions of aggregates and cement [14]. Research studies have revealed that the optimum packing density of aggregates leads to optimum mechanical properties and durability through the reduction of concrete porosity [15,16,17]. More specifically, higher packing density of aggregates leads to higher strength and improved durability of hardened concrete through reduction in the $w / c$ while maintaining the same workability [5]. Research has also shown that strength is function of the ratio of the packing density (aggregate volume fraction) in a concrete mixture to its maximum 
packing density, $\phi \phi_{\max }$ [5]. Accordingly, in this study, sorptivity is related to the packing density ratio of aggregates as follows (Equation 5):

$$
\mathrm{S} \propto\left(1-\phi / \phi_{\max }\right)
$$

Where: $\phi$ is the volume fraction of aggregates; and $\phi_{\max }$ is the maximum packing density of aggregates. An increase in $\phi \phi_{\max }$ should lead to a reduction in concrete sorptivity when other variables are fixed. The maximum packing density is function of the size, shape, volume fraction of solid particles in the mix, and the method of compaction $[5,16]$. Maximum packing density can be estimated using the Compressible Packing Model (CPM), developed by de Larrard [5], which was revealed to give good predictability for concrete mixtures.

\subsection{Sorptivity Model Final Form}

Combining the relationships presented (equations 2 to 5) and using statistical regression, yields the following proposed fundamental model for predicting the sorptivity of concrete (Equation 6):

$$
\mathrm{S}=\mathrm{A} /\left(\alpha-\alpha_{\mathrm{cr}}\right)\left[\mathrm{B}^{\left(\mathrm{w}+\mathrm{v}_{\mathrm{a}}\right) / \mathrm{c}}\left(1-\phi / \phi_{\max }\right)\right], \alpha>\alpha_{\mathrm{cr}}
$$

The calibration constant $A$ depends on the nature of the Sorptivity test and its unit is in $\mathrm{mm} / \mathrm{s}^{1 / 2}$. The calibration constant $B$ is a dimensionless term, which depends on the shape of the tested specimen and the test conditions. The calibration constants $A$ and $B$ are determined by minimizing the model standard error between the model predictions and measured experimental data. All other ratios given in equation 6 are dimensionless terms.

\section{Experimental Program}

The experimental program was developed to evaluate the applicability and accuracy of the proposed model in predicting the sorptivity of concrete. Traditional design variables typically used in proportioning concrete mixtures, including the water to cementing materials ratio, amount of water content, and air entrainment, were adopted for the design of the experimental program. A high range water reducer (HRWR) was also utilized to improve the workability of dry mixes.

\subsection{Concrete Mixture Design}

A total of six concrete mixtures given in Table 1 were proportioned following ACI 211 [18] guidelines with $w / c$ of $0.25,0.3$, and 0.4 . For the dry mixes, the amount of HRWR was varied to achieve a slump between 75 and 100 $\mathrm{mm}$ to ensure an adequate level of workability while avoiding segregation. The cementitious materials content ranged from 375 to $600 \mathrm{~kg} / \mathrm{m}^{3}$. The table also presents the amounts of cement, coarse aggregate, (CA), fine aggregates (FA). Air entraining admixture (AEA) was added to mix \# 4 and mix \# 5 at a rate of $80 \mathrm{ml} / 100 \mathrm{~kg}$ of cement.

\subsection{Materials}

This section presents the details for all materials used in concrete mixes including their technical properties. Both of the coarse aggregate (CA) and fine aggregate (FA) are crushed limestone. The maximum aggregate size of CA is $19 \mathrm{~mm}$. FA consist of well-graded local sand. Bulk density, specific gravity, and absorption for CA and FA were determined following ASTM C127 [19] and ASTM C128 [20] standards, respectively. Specific gravity, absorption value and bulk density for the $19 \mathrm{~mm}$ CA are 2.68, 1.2\% and $1600 \mathrm{~kg} / \mathrm{m}^{3}$, respectively. Fineness modulus, specific gravity, absorption values and bulk density for the FA are 2.82, $2.67,2.5 \%$ and $1800 \mathrm{~kg} / \mathrm{m}^{3}$, respectively. The particle size distributions of CA and FA were measured and calculated using the sieve analysis procedure and were found to conform to the ASTM C136/C136M [21] specification requirements, as shown in Figure 1. The cement used is Type I/II Portland cement with a specific gravity of 3.15 and meeting ASTM C150/C150M [22]. The HRWR used is Master-Glenium 7920 (from BASF), a Polycarboxylate type of admixture, which meets the requirements of ASTM C494/C494M [23] and the air-entraining admixture used meets the requirements of ASTM C260/C260M [24].

Table 1. Concrete Mixture Design Composition

\begin{tabular}{|c|c|c|c|c|c|c|}
\hline MIX \# & $w / c$ & $\begin{array}{c}\text { Water } \\
\left(\mathrm{kg} / \mathrm{m}^{3}\right)\end{array}$ & $\begin{array}{c}\text { Cement } \\
\left(\mathrm{kg} / \mathrm{m}^{3}\right)\end{array}$ & CA $\left(\mathrm{kg} / \mathrm{m}^{3}\right)$ & FA $\left(\mathrm{kg} / \mathrm{m}^{3}\right)$ & $\begin{array}{c}\text { HRWR } \\
(\mathrm{ml} / 100 \mathrm{~kg} \text { cement })\end{array}$ \\
\hline 1 & 0.30 & 150 & 500 & 960 & 852 & 606 \\
\hline 2 & 0.25 & 150 & 600 & 960 & 852 & 389 \\
\hline 3 & 0.40 & 150 & 375 & 960 & 860 & 215 \\
\hline 4 & 0.40 & 150 & 375 & 960 & 687 & 0 \\
\hline 5 & 0.40 & 184 & 460 & 960 & 693 & 0 \\
\hline 6 & 0.40 & 205 & 513 & 960 & & 370 \\
\hline
\end{tabular}




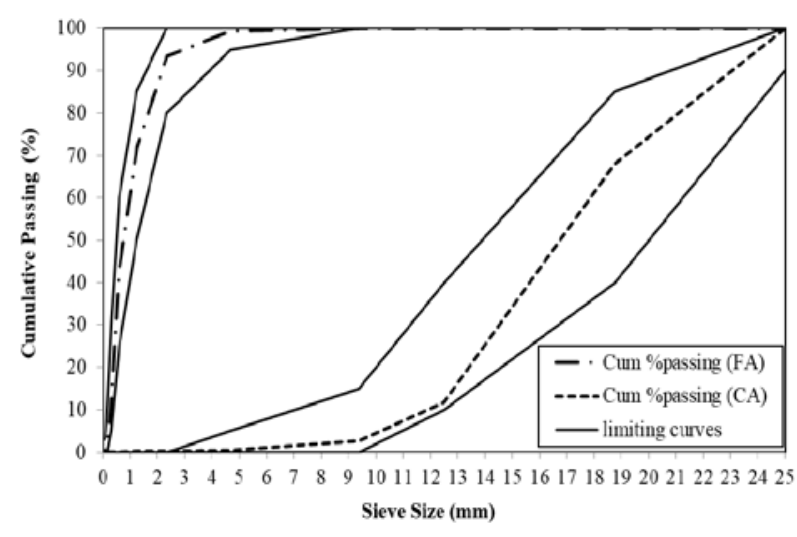

Figure 1. Aggregates Particles Size Distribution

\subsection{Experimental Procedure}

The same experimental procedure was followed for all concrete mixtures and includes mixing, placing, consolidating, curing and testing. Mixing and placing followed ASTM C192/C192M [25]. The slump and air content were measured for each concrete mixture as per ASTM C143/C143M [26] and ASTM C231/C231M [27], respectively. After casting and placing, the specimens were immediately sealed and moved to a standard curing room with relative humidity in excess of $95 \%$ and temperature of $23^{\circ} \mathrm{C}$. For every mixture, 100 x $200 \mathrm{~mm}(4 \times 8$ in.) standard cylinders were cast, compacted by rodding and surface finished in accordance with ASTM C192/C192M [25]. The concrete compressive strength was also evaluated at 28 days following ASTMC39/C39M [28] to ensure good concrete performance and achieving mix design proportioning requirements. Conducting the sorptivity test, which includes cutting, conditioning, and testing, was done in accordance with ASTM C1585 [3].

\subsection{Sorptivity Samples Preparation and Testing}

In accordance with ASTM C1585 [3], Sorptivity specimens were prepared by cutting discs of $100 \pm 6 \mathrm{~mm}$ in diameter and $50 \pm 3 \mathrm{~mm}$ in length. Using a Saw, discs were cut from the interior of the $200 \mathrm{~mm}$ long cylinders to ensure that the specimens are representative samples of the concrete and to ensure consistency. Prior to the test, the specimens were placed in a desiccator oven at a temperature of $50 \pm 2^{\circ} \mathrm{C}$ and a relative humidity $\mathrm{RH}$ of $80 \pm$ $3 \%$ for 3 days. The perimeter of each disc was then sealed using electric tape. At the start of the test, the disc was placed in contact with water at one end while open to air at the other end. Mass gain due to water sorption was measured at certain intervals for the first six hours. Figure 2 presents the schematic diagram of the water sorptivity test setup.

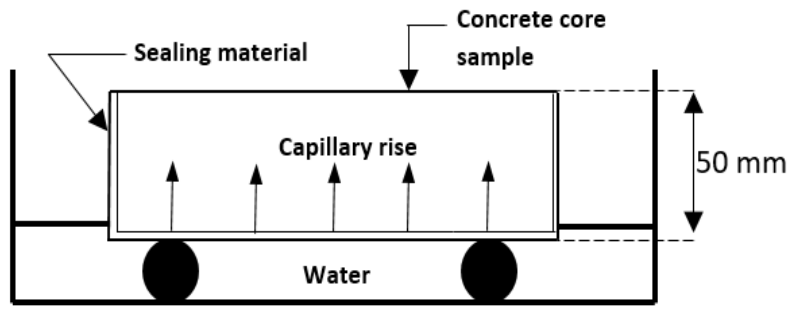

Figure 2. Schematic Diagram of the Water Sorptivity Test

\section{Experimental Results and Discussion}

The proposed sorptivity model requires determining of the calibration constants. Model Calibration was carried out by minimizing the standard error $(\sigma)$ between the model predictions and the measured experimental data. The standard error, which provides a global assessment of the model predictions, is defined in Equation 7 [29]:

$$
\sigma=\left\{\Sigma\left[\mathrm{S}_{\mathrm{m}}(\mathrm{i})-\mathrm{S}_{\exp }(\mathrm{i})\right]^{2} /(\mathrm{n}-\mathrm{p})\right\}^{1 / 2}
$$

Where parameters $S_{m}(i)$ and $S_{\text {exp }}(i)$ refer to the model and experimental sorptivity values that correspond to mix $i$, respectively. Parameters $n$ and $p$ refer to the number of tested points and the number of model constants, respectively. This application provides an assessment of the goodness of fit and the soundness of the proposed model. In addition, the correlation coefficient $\left(R^{2}\right)$, which provides a measure of the proportion of model variability, was also calculated. Such measures permit assessment of the capabilities of the proposed model in predicting the trends reported in the literature. Using the initial absorption (up to 6 hours) experimental data obtained in this study, the initial rate of absorption was determined for each mix using linear regressive analysis as outlined in ASTM C1585 [3]. Consequently, the proposed sorptivity model was calibrated and the calibration constants A and B were found equal to $0.00021 \mathrm{~mm} / \mathrm{s}^{1 / 2}$ and 371 , respectively. The corresponding standard error and correlation coefficient were $0.00039 \mathrm{~mm} / \mathrm{s}^{1 / 2}$ and 0.89 , respectively.

Table 2. Results of Experimental Testing

\begin{tabular}{|c|c|c|c|c|}
\hline MIX \# & $\begin{array}{c}\text { Slump } \\
(\mathrm{mm})\end{array}$ & $\begin{array}{c}\text { Air } \\
\text { Content } \\
(\%)\end{array}$ & $\begin{array}{c}\text { Compressive } \\
\text { Strength } \\
(\mathrm{MPa})\end{array}$ & $\begin{array}{c}\text { Sorptivity } \\
\left(\mathrm{mm} / \mathrm{s}^{1 / 2}\right)\end{array}$ \\
\hline 1 & 80 & 2.2 & 97.0 & 0.00088 \\
\hline 2 & 95 & 3.0 & 99.4 & 0.00073 \\
\hline 3 & 75 & 1.5 & 72.1 & 0.00110 \\
\hline 4 & 90 & 6.4 & 45.6 & 0.00294 \\
\hline 5 & 65 & 3.5 & 55.8 & 0.00181 \\
\hline 6 & 90 & 2.2 & 55.8 & 0.00123 \\
\hline
\end{tabular}

Table 2 presents the experimental results for each mix, which includes the average values for air content, slump, compressive strength at 28 days, and sorptivity. As shown, all the concrete mixes achieved compressive strengths 
exceeding $40 \mathrm{MPa}$, which confirms good concrete performance.

Figure 3 is a visual illustration of the sorptivity results obtained for each mix. As expected, mix \# 2 having the lowest w/c of 0.25 gave the highest compressive strength and the lowest sorptivity value. This is followed by mix \# 1 having a w/c of 0.3 resulting in the second highest compressive strength and consequently the second lowest sorptivity value. Mix \# 4 gave the lowest compressive strength and highest sorptivity value due to the higher air content (6.4\%) in comparison with other mixes. This is followed by mix \#5 with an air content of 3.5\%. Mixes \#3 and 6 are similar as they both have the same w/c and do not contain entrained air and HRWR. However, mix \#3 gave better results due to a higher packing density ratio for the aggregates $\left(\phi_{1} \phi_{\max }\right)$ resulting in less amount of voids.

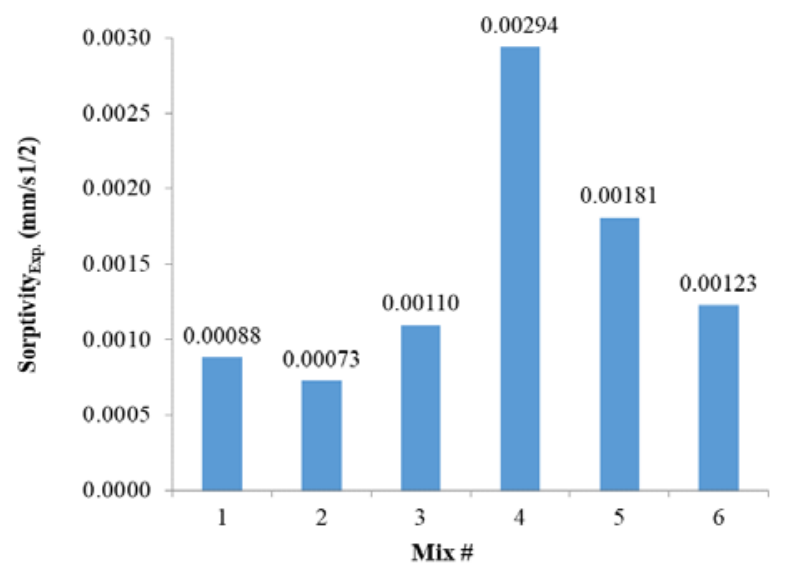

Figure 3. Sorptivity Experimental Results

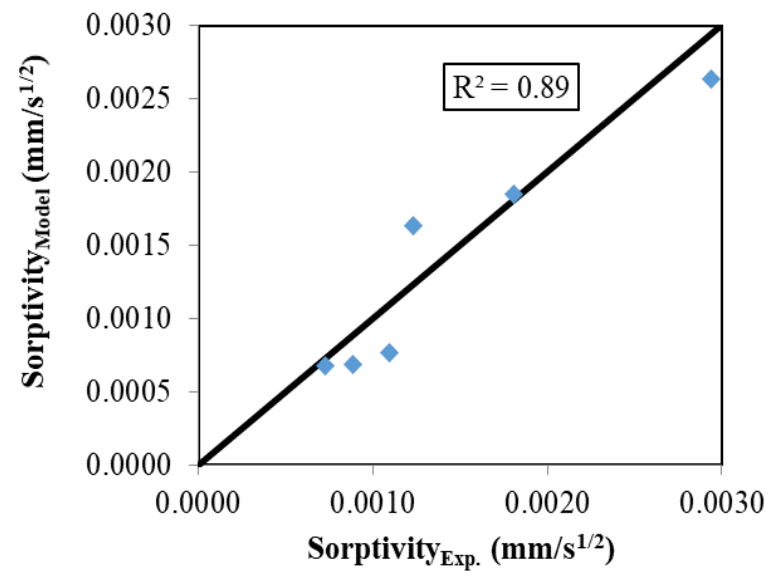

Figure 4. Sorptivity Model vs. Experiment

Figure 4 shows the goodness of fit of the proposed model in comparison to the measured experimental data. The corresponding standard error and correlation coefficient were $0.00039 \mathrm{~mm} / \mathrm{s}^{1 / 2}$ and 0.89 , respectively. These results provide evidence of the model ability to predict the sorptivity of concrete. The soundness of the model was also evaluated through comparing the predicted sorptivity values to the residual values as shown in Figure 5. Results reveal no visible patterns or outliers, which confirms the good predictability of the proposed model. In addition, statistical evaluation results reveal that the proposed model is significant in outcome predictions. The model p-value is found to be less than 0.001 .

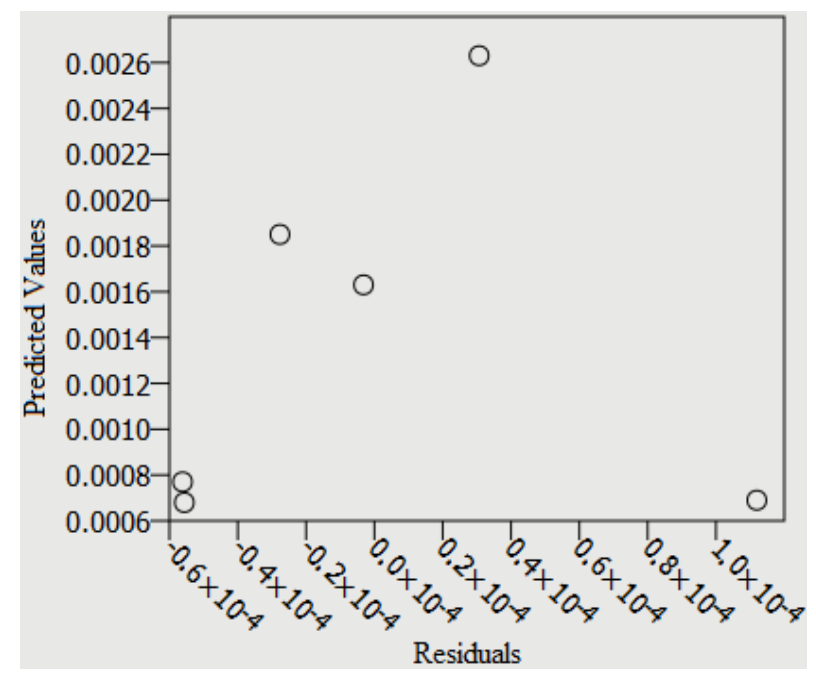

Figure 5. Model Assessment- Residual Plot

\section{Conclusions}

In this study, a microstructure sorptivity model for predicting the rate of water absorption in concrete has been formulated, calibrated and validated. The sorptivity model is characterized by the following main features:

- Packing density was incorporated into the sorptivity model to account for particles gradation and mixture proportions.

- A cement hydration model developed by Schindler and Folliard [8] was adopted and incorporated into the sorptivity model to account for the chemical and mechanical properties of cement.

- Concrete capillary pores and air pores (entrapped and entrained) were modeled through incoporating the relationship developed by Popovics [13].

Model evaluation revealed the following conclusions:

- The sorptivity model provides a good fit to the experimental data. In addition, it does not contain outliers or any discerning pattern.

- The standard error is $0.00039 \mathrm{~mm} / \mathrm{s}^{1 / 2}$ only. The corresponding correlation coefficient is greater than 0.89 .

- A statistical model evaluation revealed that the proposed model is significant in its prediction of the outcome. The model p-value was found to be less than 0.001 .

Model calibration constants $A$ and $B$ depend on the nature of the Sorptivity test, and the shape of the tested 
specimen and test conditions, respectively. These constants were determined by minimizing the model standard error between the model predictions and measured experimental data. It should be noted that the values determined for these constants are applicable for cylindrical specimens tested following the ASTM standards. Re-calibration of these constants will be required for different testing methods and specimen shapes.

This predictive sorptivity model can be utilized in the design of concrete mixtures to meet specific durability requirements as a priority and ensure quality control before concrete is cast. Furthermore, the proposed model can be utilized to improve the durability prediction of concrete mixtures.

\section{Notations}

$A$ and $B$ : calibration constants

$A_{f}$ : cross-sectional area in contact with fluid

$c, w$ : quantity of cement and water in the concrete mix, respectively

$M(t)$ : the mass of fluid uptake

$n$ : number of test points

$p$ : number of model constants

$S$ Sorptivity

$S_{m}(i), S_{\text {exp }}(i)$ : model and experimental sorptivity values corresponding to mix $i$, respectively

$t$ : time

$V_{a}$ : volume fraction of air in the concrete mix

$w / c$ : water to cementing materials ratio

$\alpha$ degree of hydration of cement

$\alpha_{c r}$ : critical degree of hydration of cement

$\rho$ : density of fluid

$\phi$ : volume fraction of aggregates

$\phi_{\max }$ maximum packing density of aggregates

\section{REFERENCES}

[1] E. Elawady, A. El Hefnawy, R. Ibrahim. Comparative study on strength, permeability and sorptivity of concrete and their relation with concrete durability, International Journal of Engineering and Innovative Technology, Vol.4, No.4, 132-139, 2014.

[2] S. E. Chidiac, O. Maadani, A. G. Razaqpur, N. P. Mailvaganam. Correlation of rheological properties to durability and strength of hardened concrete, Journal of Materials in Civil Engineering, Vol.15, No.4, 391-399, 2003.

[3] ASTM C1585-13: Standard test method for measurement of rate of absorption of water by hydraulic-cement concretes, ASTM, West Conshohocken, PA, 2013.

[4] P. McGrath. Development of test methods for predicting chloride penetration into high performance concrete. Ph.D. Thesis, Department of Civil Engineering, University of
Toronto, 1996.

[5] F. de Larrard. Concrete Mixture Proportioning: A Scientific Approach, Spon Press, London, 1999.

[6] S.E. Chidiac, F. Moutassem, F. Mahmoodzadeh. Compressive strength model for concrete, Journal of Magazine of Concrete Research, Vol.65, No.9, 557-572, 2013.

[7] P. K. Mehta, P. Monteiro. Concrete: Microstructure, Properties, and Materials, 3rd edn. McGraw-Hill, New York, USA, 2006.

[8] A. K. Schindler, K. J. Folliard. Heat of hydration models for cementitious materials. ACI Materials Journal, Vol.102, No.1, 24-33, 2005.

[9] A. Beek, K. Breugel, M. A. Hilhorst. Monitoring system for hardening concrete based on dielectric properties, Proceedings of the International Conference Utilizing Ready Mix Concrete and Mortar, University of Dundee, Scotland, 303-312, 1999.

[10] R. O. Rasmussen, J. M. Ruiz, D. K. Rozycki, B. F. McCullough. Constructing High-performance Concrete Pavements with FHWA HIPERPAV Systems analysis Software, Transportation Research Board, Washington DC, USA, 11-20, 2002.

[11] T. C. Powers, T. L. Brownyard. Studies of the physical properties of hardened Portland cement paste. Proceedings of the American Concrete Institute, Vol.18, No.2, 669-712, 1946.

[12] L. D. Abrams. (cited by A. M. Neville, 1981). Properties of Concrete, 3rd ed. Pitman Publishing, London, 1919.

[13] S. Popovics. New formulas for the prediction of the effect of porosity on concrete strength, ACI Materials Journal, Vol.82, No.2, 136-146, 1985.

[14] F. de Larrard, A. Belloc. The influence of aggregate on the compressive strength of normal and high-strength concrete, ACI Materials Journal, Vol.94, No.5, 417-425, 1997.

[15] V. Johansen, P. J. Andersen. Particle packing and concrete properties, Materials Science of Concrete II, American Ceramic Society, Westerville, Ohio, 111-147, 1996.

[16] H. Wong, A. Kwan. Packing density: a key concept for mix design of high performance concrete. Proc., Materials Science and Technology in Engineering Conference (MaSTEC), Hong Kong, 2005.

[17] C. T. Tasi, S. Li, C. L. Hwang. The effect of aggregate gradation on engineering properties of high performance concrete, Journal of ASTM International, Vol.2, No.3, 1-12, 2006.

[18] ACI (American Concrete Institute). Standard practice for selecting proportions for normal, heavyweight, and mass concrete, ACI 211.1-91, Farmington Hills, MI, 1991.

[19] ASTM C127-15: Standard test method for specific gravity and absorption of coarse aggregate, ASTM International, West Conshohocken, PA, 2015.

[20] ASTM C128-15: Standard test method for specific gravity and absorption of fine aggregate, ASTM, West Conshohocken, PA, 2015. 
[21] ASTM C136-14: Standard test method for sieve analysis of fine and coarse aggregates, ASTM, West Conshohocken, PA, 2014.

[22] ASTM C143-15: Standard test method for slump of hydraulic-cement concrete, ASTM, West Conshohocken, PA, 2015.

[23] ASTM C150-16: Standard specification for portland cement, ASTM, West Conshohocken, PA, 2016.

[24] ASTM C494-15: Standard specification for chemical admixtures for concrete, ASTM, West Conshohocken, PA, 2015.

[25] ASTM C260-10: Air-entraining admixtures for concrete, ASTM, West Conshohocken, PA, 2010.

[26] ASTM C192-16: Making and curing concrete specimens in the laboratory, ASTM, West Conshohocken, PA, 2016.

[27] ASTM C143-15: Standard test method for slump of hydraulic-cement concrete, ASTM, West Conshohocken, PA, 2015.

[28] ASTM C231-16: Standard test method for air content of freshly mixed concrete by the pressure method, ASTM, West Conshohocken, PA, 2016.

[29] ASTM C39-16: Standard test method for compressive strength of cylindrical specimens, ASTM, West Conshohocken, PA, 2016.

[30] ASTM C39-16: Standard test method for compressive strength of cylindrical specimens, ASTM, West Conshohocken, PA, 2016.

[31] D. C. Montgomery, G. C. Runger. Applied Statistics and Probability for Engineers, 3rd edn. Wiley, New York, USA, 2003. 